\title{
Ratiometric Fluorescence Sensing of Metals based on Thiazole derivatives
}

\section{Hong-Seok Kim*}

Department of Applied Chemistry, Kyungpook National University, Daegu 702701, Korea, (kimhs@knu.ac.kr)

The design and synthesis of chemosensors for highly noxious heavy and transition metal ions are currently a task of prime importance for medical, environmental, and biological applications. Presently, one of the most attractive approaches focuses on the research of novel colorimetric and fluorescent metal ion sensors, which allow naked-eye change of color and fluorescent emission upon metal ion binding without any use of a spectroscopic instrument. $\mathrm{Al}^{3+}$ is the third most abundant element in the lithosphere and its compounds are dispersed widely in the environment. Dietary aluminum is ubiquitous but mounting evidence in the literature suggests that aluminum is toxic to many living beings including humans. ${ }^{[1]} \mathrm{Al}^{3+}$ toxicity causes bone and joint diseases through defective mineralization and osteomalacia, ${ }^{[2]}$ neuronal disorders leading to dialysis encephalopathy, dementia, myopathy, idiopathic Parkinson's disease, impairment of memory and Alzheimer' s disease. ${ }^{[3]}$

Previously, the synthesis and $\mathrm{Zn}^{2+}$ or $\mathrm{Cu}^{2+}$ sensing properties of several thiazole based chemosensors were reported. $^{[4,5,6]}$ Among them, the selectivity for cations can be controlled by changing the moiety at position-4 of the thiazole ring. Herein we describe new thiazole-based sensors for detection of $\mathrm{Zn}^{2+}$, $\mathrm{Cu}^{2+}$ and $\mathrm{Al}^{3+}$.

\section{References}

1. J. R. J. Sorenson, I. R. Campbell, L. B. Tepper, and R. D. Lingg: Environ. Health Perspect. 8 (1974) 3.

2. G. C. Woodson: Bone 22 (1998) 695.

3. B. Wang, W. Xing, Y. Zhao, and X. Deng: Environ. Toxicol. Pharmacol. 29 (2010) 308.

4. A. Helal, S. H. Lee, S. H. Kim, and H.-S. Kim: Tetrahedron Lett. 51 (2010) 3531.

5. A. Helal, M. H. Or Rashid, C.-H. Choi, and H.-S. Kim: Tetrahedron 68 (2012) 647.

6. A. Helal, M. H. Or Rashid, C.-H. Choi, and H.-S. Kim: Tetrahedron 67 (2011) 2794. 